Article

\title{
Cymbopogon Proximus Essential Oil Protects Rats against Isoproterenol-Induced Cardiac Hypertrophy and Fibrosis
}

\author{
Hassan N. Althurwi ${ }^{1, *}$, Maged S. Abdel-Kader ${ }^{2,3}$, Khalid M. Alharthy ${ }^{1}$, \\ Mohamad Ayman Salkini ${ }^{2}$ and Faisal F. Albaqami ${ }^{1}$ (D) \\ 1 Pharmacology and Toxicology Department, College of Pharmacy, Prince Sattam bin Abdulaziz University, \\ AlKharj 11942, Saudi Arabia; k.alharthy@psau.edu.sa (K.M.A.); f.albaqami@psau.edu.sa (F.F.A.) \\ 2 Pharmacognosy Department, College of Pharmacy, Prince Sattam bin Abdulaziz University, \\ AlKharj 11942, Saudi Arabia; mpharm101@hotmail.com (M.S.A.-K.); m.salkini@psau.edu.sa (M.A.S.) \\ 3 Department of Pharmacognosy, College of Pharmacy, Alexandria University, Alexandria 21215, Egypt \\ * Correspondence: althurwi@gmail.com; Tel.: +96-650-585-5772
}

Received: 23 March 2020; Accepted: 11 April 2020; Published: 13 April 2020

\begin{abstract}
Cardiac hypertrophy is an independent risk factor of many cardiovascular diseases. Several cardiovascular protective properties of Cymbopogon proximus have been reported. However, no reports investigating the direct effect of $C$. proximus essential oil on the heart are available. The goal of this study was to explore the cardioprotective effect of $C$. proximus on cardiac hypertrophy and fibrosis. Male albino rats were administered $C$. proximus essential oil in the presence or absence of hypertrophic agonist isoproterenol. Cardiac hypertrophy and fibrosis were assessed using real-time polymerase chain reaction (PCR) and histological examination. Pre- treatment of rats with C. proximus decreased the ratio of heart weight to body weight and gene expression of hypertrophy markers atrial natriuretic peptide (ANP), brain natriuretic peptide (BNP), and $\beta$-myosin heavy chain ( $\beta-\mathrm{MHC})$, which were induced by isoproterenol. Moreover, $C$. proximus prevented the increase in gene expression of fibrosis markers procollagen I and procollagen III and alleviated the collagen volume fraction caused by isoproterenol. The pre- treatment with C. proximus essential oil conferred cardio-protection against isoproterenol- induced cardiac hypertrophy and fibrosis.
\end{abstract}

Keywords: cardiac fibrosis; cardiac hypertrophy; cardiac remodeling; Cymbopogon proximus; isoproterenol

\section{Introduction}

Globally, cardiovascular diseases (CVDs) remain the leading cause of mortality and morbidity [1]. Although advances have been made in cardiovascular research, CVDs are still responsible for $31 \%$ of all deaths worldwide [2]. In general, cardiac diseases are viewed as a chain of events known as the CVD continuum, which if untreated, eventually leads to heart failure (HF) and sudden death $[3,4]$. Currently, more than 26 million patients have been diagnosed with HF [5]. The prognosis for patients with HF remains poor with $50 \%$ of patients dying within five years of diagnosis [6]. Cardiac hypertrophy, a thickening of the heart wall in response to increased cardiac stress, occurs early on in the CVD continuum and is considered as a compensatory response that permits normal cardiovascular function at rest $[7,8]$. However, prolonged hypertrophy is now recognized as a credible surrogate endpoint of $\mathrm{HF}$ and a major risk factor for heart disease, including coronary artery disease (CAD), arrhythmia, and hypertension [9]. Therefore, studying cardiac hypertrophy is important to identify new therapeutic options that could prevent and/or treat CVDs in the early stages.

Cymbopogon, a genus of plants with many species known for their high essential oil content, are widely distributed throughout the tropical and subtropical regions of Asia, Africa, 
and America [10]. The use of Cymbopogon species in traditional medicine is well documented. Several illnesses, such as coughs, fever, infections, cancer, and digestive disorders, have reportedly been treated using various species of Cymbopogon worldwide [10,11]. Moreover, in vivo and in vitro studies have revealed beneficial pharmacological effects of Cymbopogon spp., including anticancer, cardioprotective, anti-inflammatory, antioxidant, antidiabetic, anticholinesterase, antibacterial, and antifungal properties [12-18].

One species of interest is C. proximus (common names: Halfabar or Maharaib), a strongly aromatic common grass widely distributed in parts of Southern Egypt and Northern Sudan. C. proximus has been used for several decades by the inhabitants of these regions as a diuretic and antispasmodic agent due to its potent ability to induce smooth-muscle relaxation [19]. C. proximus reportedly possesses many biological properties, including hypoglycemic, antipyretic, bronchodilation, antibacterial, anticonvulsant, and antiemetic activities [15,20-23]. Interestingly, C. proximus has been shown to exhibit a hypotensive effect in normotensive rats and protect against nitro-L-arginine methyl ester (L-NAME)-induced hypertension [23,24]. At the cellular level, extracts of C. proximus have been shown to have antioxidant, anti-inflammatory, and antiapoptotic properties [20,22]. These findings indicate that $C$. proximus may be a potential protective agent against cardiac diseases. To the best of our knowledge, no research has evaluated the effect of $C$. proximus against cardiac remodeling with a focus on myocardial hypertrophy and fibrosis. We hypothesized that C. proximus essential oil would confer cardioprotection against isoproterenol-induced cardiac hypertrophy and fibrosis. The findings from this research may provide the first evidence for the potential use of $C$. proximus as a modulator of cardiac remodeling. This is especially important with the current need to identify new alternative medicines that are natural and safe.

\section{Results}

\subsection{Gas Chromatography-Mass Spectrometry (GC-MS) Analysis}

Analysis of the C. proximus essential oil by GC-MS identified forty different chemical constituents, which represented $93.27 \%$ of the total oil extract. The main components included elemol (23.54\%), piperitone (19.86\%), $\alpha$-eudesmol (7.63\%), and $\beta$-eudesmol $(11.35 \%)$, which together comprised $62.38 \%$ of the oil. A complete listing of the GC-MS results is shown in Table 1.

Table 1. Components of Cymbopogon proximus essential oil.

\begin{tabular}{ccc}
\hline No. & Component Name & Yield $\mathbf{\%}^{\mathbf{1}}$ \\
\hline 1 & Elemol & 23.54 \\
2 & Piperitone & 19.86 \\
3 & $\beta$-Eudesmol & 11.35 \\
4 & $\alpha$-Eudesmol & 7.63 \\
5 & $\beta$-Elemene & 4.61 \\
6 & T-Cadinol & 3.87 \\
7 & Terpinolene & 3.48 \\
8 & $\beta$-Selinenol & 2.55 \\
9 & 3-Cyclohexen-1-one, 2-isopropyl-5-methyl & 2.44 \\
10 & 4-Carene & 1.66 \\
11 & Shyobunol & 1.46 \\
12 & $\alpha$-Terpineol & 1.21 \\
13 & Cadina-1(10),4-diene & 1.13 \\
14 & $(-)$-Guaia-6,9-diene & 0.75 \\
15 & Limonene & 0.66 \\
16 & Terpinolene & 0.56 \\
17 & $\beta-C a r y o p h y l l a n e, 4,8-e p o x y$ & 0.52 \\
18 & cis-Calamenene & 0.51 \\
19 & trans-Geranylgeraniol & 0.49 \\
20 & Epi-Cubenol & 0.49 \\
\hline
\end{tabular}


Table 1. Cont

\begin{tabular}{ccc}
\hline No. & Component Name & Yield $\mathbf{~}^{\mathbf{1}}$ \\
\hline 21 & Espatulenol & 0.49 \\
22 & 2-Carene & 0.44 \\
23 & Cuparene & 0.38 \\
24 & Thymol & 0.30 \\
25 & Z)- $\beta$-ocimene & 0.29 \\
26 & Ermacrene B & 0.26 \\
27 & $\alpha$-Dihydroagarofuran & 0.26 \\
28 & $\gamma$-Muurolene & 0.26 \\
29 & Caryophyllene oxide & 0.24 \\
30 & Shyobunol & 0.23 \\
31 & $\alpha$-Selinene & 0.20 \\
32 & Espatulenol & 0.19 \\
33 & $p$-Mentha-1,5-dien-8-ol & 0.15 \\
34 & Anethole & 0.14 \\
35 & Cadinene & 0.13 \\
36 & Aromandendrene & 0.12 \\
37 & d-Elemene & 0.12 \\
38 & Isocaryophyllene & 0.12 \\
39 & Allo-Ocimene & 0.11 \\
40 & $\alpha$-Amorphene & 0.11 \\
\hline
\end{tabular}

${ }^{1}$ Percentages of yield were calculated based on concentrations obtained according to gas chromatography using an HP-5MS capillary column. The quantitative estimation of each compound was determined based on computerized peak area measurements.

\subsection{Effect of C. Proximus Oil and/or Isoproterenol on Body and Heart Weights}

Isoproterenol treatment caused a significant increase of $23 \%$ in the ratio of heart weight to body weight (HW/BW) compared with that of the control group $(p<0.001)$. On the other hand, rats pretreated with C. proximus oil displayed a $69 \%$ reduction in the isoproterenol-mediated increase of HW/BW compared with that of the isoproterenol group $(p=0.017)$. Furthermore, no significant difference in HW/BW was found between the control group and the group treated with C. proximus oil alone (Figure 1).

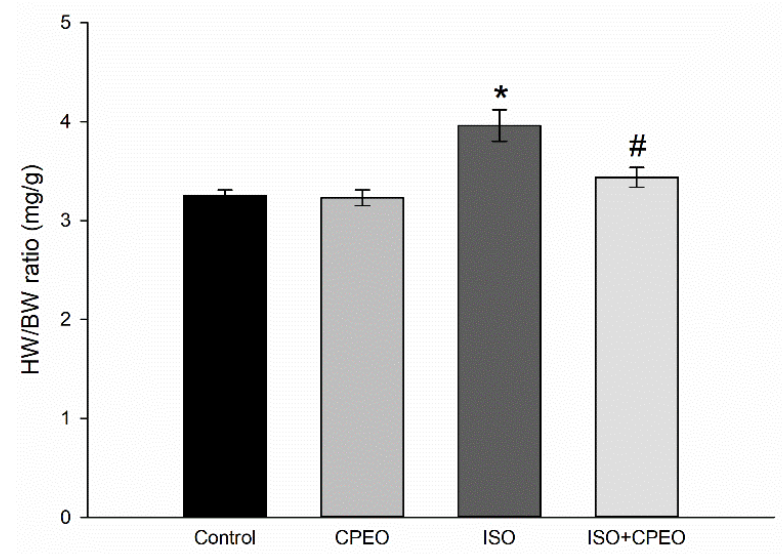

Figure 1. Effect of Cymbopogon proximus essential oil (CPEO) on body weight (BW) and heart weight (HW) of rats. Male albino rats were injected intraperitoneally daily with vehicle (saline + olive oil) as the control, CPEO (800 $\mu \mathrm{L} / \mathrm{kg} / \mathrm{d})$, isoproterenol (ISO; $5 \mathrm{mg} / \mathrm{kg})$, or CPEO $(800 \mu \mathrm{L} / \mathrm{kg} / \mathrm{d})$ plus isoproterenol $(5 \mathrm{mg} / \mathrm{kg}$ ). CPEO administration was started $4 \mathrm{~d}$ prior to isoproterenol administration and continued concurrently thereafter for an additional $3 \mathrm{~d}$. The HW/BW ratio $(\mathrm{mg} / \mathrm{g})$ was determined for each animal after $7 \mathrm{~d}$ of treatment with vehicle, CPEO, ISO, or a combination of ISO+CPEO. The results are presented as the means of six independent experiments \pm SEM. ${ }^{*} p<0.05$ compared to control, $\# p<0.05$ compared to ISO-treated rats. 


\subsection{Effect of C. Proximus Oil and/or Isoproterenol on Hypertrophy Markers}

In addition to increased heart mass, pathological cardiac hypertrophy is characterized by the activation of the fetal gene program, thereby changing the expression of different genes including ANP, BNP, and $\beta$-MHC. Thus, the expression of these genes is one of the most consistent markers of pathological cardiac hypertrophy [25-27]. To investigate whether $C$. proximus oil and/or isoproterenol treatment altered the expression level of hypertrophy markers, we measured cardiac expression of $\mathrm{ANP}, \mathrm{BNP}$, and $\beta$-MHC. Isoproterenol alone caused significant induction of ANP, BNP and $\beta$-MHC expression with mRNA levels increasing 52-fold $(p<0.001), 12.5$-fold $(p<0.001)$, and 0.7-fold $(p=0.02)$, respectively (Figure 2). However, relative to those in isoproterenol-treated rats, pretreatment with $C$. proximus oil significantly decreased the isoproterenol-mediated induction of ANP, BNP and $\beta$-MHC by $73 \%(p=0.004), 59 \%(p=0.007)$, and 91\% ( $p=0.024)$, respectively (Figure 2$)$.
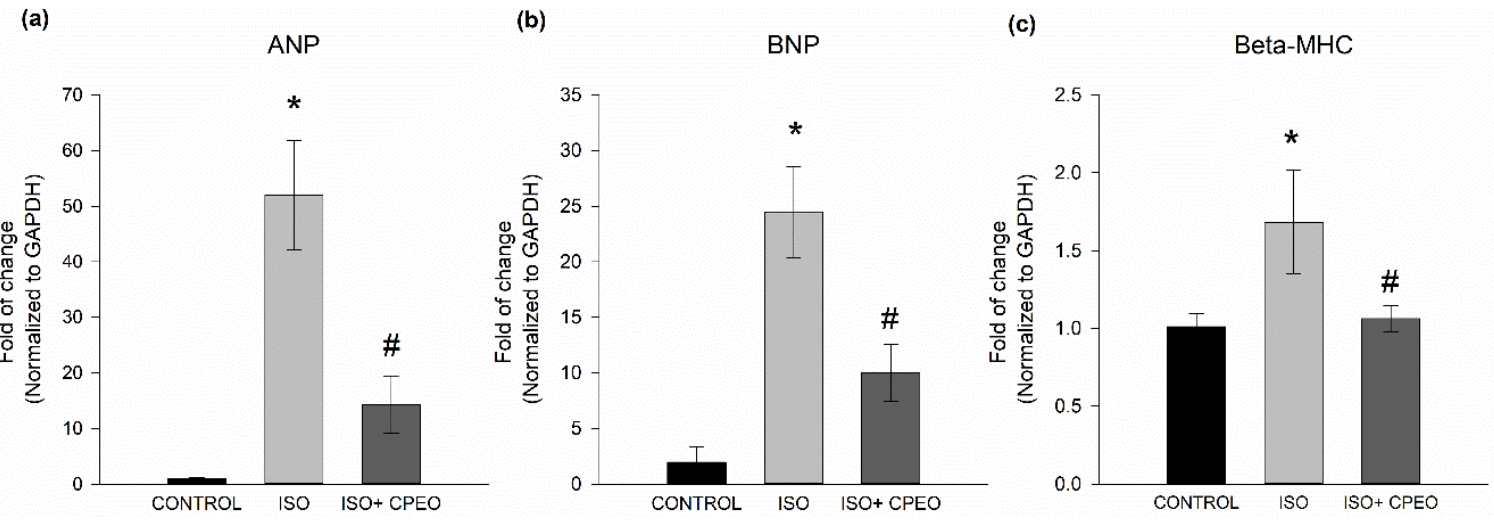

Figure 2. Effect of Cymbopogon proximus essential oil (CPEO) and/or isoproterenol (ISO) on hypertrophy markers. Male albino rats were injected intraperitoneally daily with vehicle (Control), PEO (800 $\mu \mathrm{L} / \mathrm{kg} / \mathrm{d})$, ISO (5 mg/kg), or CPEO $(800 \mu \mathrm{L} / \mathrm{kg} / \mathrm{d})$ plus ISO $(5 \mathrm{mg} / \mathrm{kg})$. Oil administration was started $4 \mathrm{~d}$ prior to ISO administration and continued concurrently thereafter for an additional $3 \mathrm{~d}$. Expression of hypertrophic genes ANP (a), BNP (b), and $\beta$-MHC (c) in heart tissue based on mRNA levels measured using quantitative real-time polymerase chain reaction. The results are presented as the means of six independent experiments \pm SEM. ${ }^{*} p<0.05$ compared to control, $\# p<0.05$ compared to ISO-treated rats.

\subsection{Effect of C. Proximus Oil and/or Isoproterenol on Myocardial Architecture}

Histopathological examination of cardiac tissue sections from the control group revealed typical cell distribution and normal myocardium architecture, demonstrating variable fiber diameters and central positions of the nuclei. However, examination of cardiac tissue sections from isoproterenoltreated rats revealed moderate cardiomyocyte degeneration, necrosis, pyknosis, and a $71 \%$ increase in cross-sectional area of cardiac myocytes cells compared to that of the control group $(p<$ 0.001). Pretreatment with C. proximus oil resulted in a less severe necrosis and a $33 \%$ decrease in cross-sectional area of cardiac myocytes compared to that of the isoproterenol group $(p=0.005$; Figure 3). However, the pretreatment with $C$. proximus oil did not restore this response to the control levels $(p<0.001)$. 
(a)

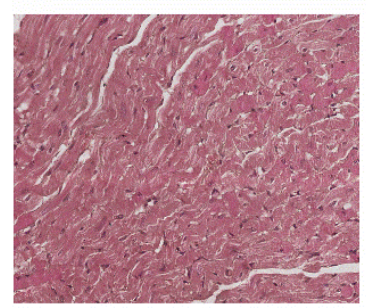

Control

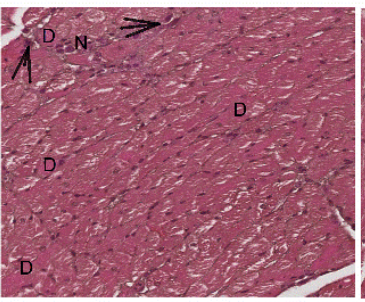

ISO (b)

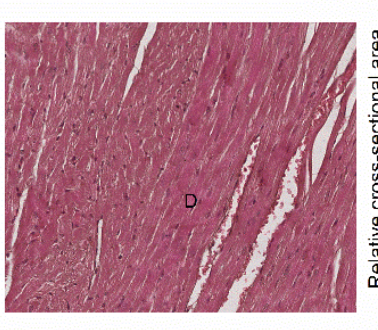

ISO + CPEO

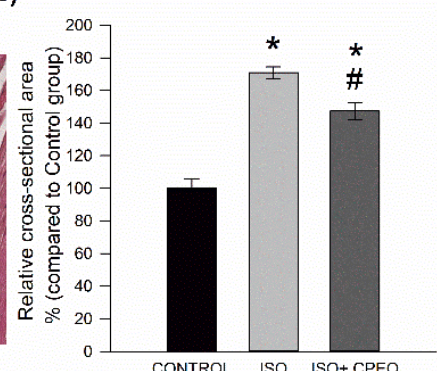

Figure 3. Effect of Cymbopogon proximus essential oil (CPEO) and/or isoproterenol (ISO) on myocardial architecture. Male albino rats were injected intraperitoneally daily with vehicle (Control), CPEO $(800 \mu \mathrm{L} / \mathrm{kg} / \mathrm{d})$, ISO (5 mg/kg), or CPEO (800 $\mu \mathrm{L} / \mathrm{kg} / \mathrm{d})$ plus ISO (5 mg/kg). Oil administration was started $4 \mathrm{~d}$ prior to ISO administration and continued concurrently thereafter for an additional $3 \mathrm{~d}$. Histological examination and pathological changes in heart tissue. (a) Representative images of hematoxylin and eosin (H\&E)-stained fields are shown for the left ventricles of rats of the control group and rats treated with ISO+CPEO or ISO alone (magnification, $\times 200$ ), (necrosis $(\mathrm{N})$; degeneration (D); pyknotic changes in the nuclei (arrows)) (b) Mean cross-sectional areas of cardiomyocytes from left ventricles of rats from the indicated experimental groups were calculated and are shown. The results are presented as the means of four independent experiments \pm SEM. ${ }^{*} p<0.05$ compared to control, \# $p<0.05$ compared to ISO-treated rats.

\subsection{Effect of C. Proximus Oil and/or Isoproterenol on Myocardial Fibrosis}

To assess the degree of myocardial fibrosis in response to C. proximus oil and/or isoproterenol, heart sections were stained with Masson's trichrome and the percentages of fibrotic tissue in the images were determined using ImageJ software. Collagen volume fraction (CVF) values in the isoproterenol-treated group increased $242 \%$ compared with that in the control group $(p<0.001)$. However, the pretreatment with $C$. proximus oil significantly reduced the elevated CVF levels induced by isoproterenol by $66 \%$ $(p=0.006)$ (Figure 4$)$.

(a)

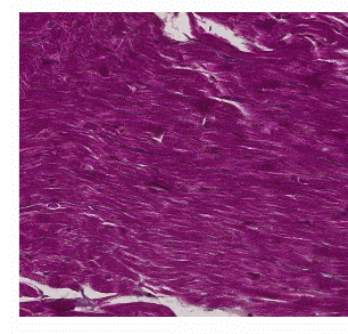

Control

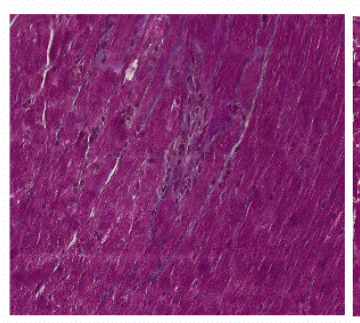

ISO

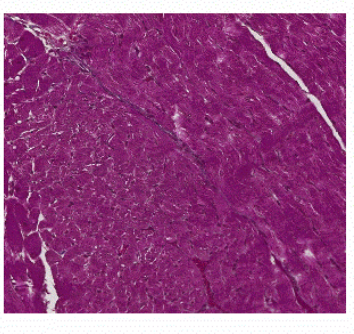

ISO + CPEO (b)

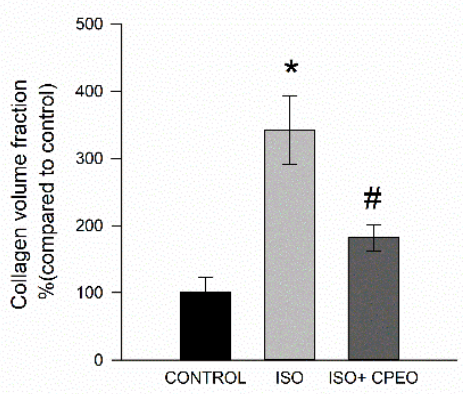

Figure 4. Effect of Cymbopogon proximus essential oil (CPEO) and/or isoproterenol (ISO) on myocardial fibrosis. Male albino rats were injected intraperitoneally daily with vehicle, CPEO ( $800 \mu \mathrm{L} / \mathrm{kg} / \mathrm{d})$, ISO (5 $\mathrm{mg} / \mathrm{kg})$, or CPEO $(800 \mu \mathrm{L} / \mathrm{kg} / \mathrm{d})$ plus ISO $(5 \mathrm{mg} / \mathrm{kg})$. Oil administration was started $4 \mathrm{~d}$ prior to ISO administration and continued concurrently thereafter for an additional $3 \mathrm{~d}$. Histological analysis and pathological changes in cardiac tissue. (a) Representative Masson's trichrome staining of left ventricles of control group rats and rats treated with ISO+CPEO or ISO alone. (b) Quantitative analysis of myocardial collagen volume fraction $(\mathrm{CVF})$ in the left ventricles of rats of the experimental and control groups. The results are presented as the means of four independent experiments \pm SEM. ${ }^{*} p<0.05$ compared to control, \# $p<0.05$ compared to ISO-treated rats.

\subsection{Effect of C. Proximus Oil and/or Isoproterenol on the Level of Fibrosis Markers}

To further assess the extent of changes in myocardial fibrosis mediated by C. proximus oil and/or isoproterenol, we measured mRNA levels of fibrotic markers Pro I and Pro III. Isoproterenol treatment 
resulted in significant induction of Pro I and Pro III expression with 17.8-fold $(p<0.001)$ and 17.9-fold increases $(p=0.004)$, respectively. However, these increases of Pro I and Pro III mRNA levels were significantly reduced by $80 \%(p<0.001)$ and $77 \%(p=0.004)$, respectively, when the rats were pretreated with C. proximus oil (Figure 5).

(a)

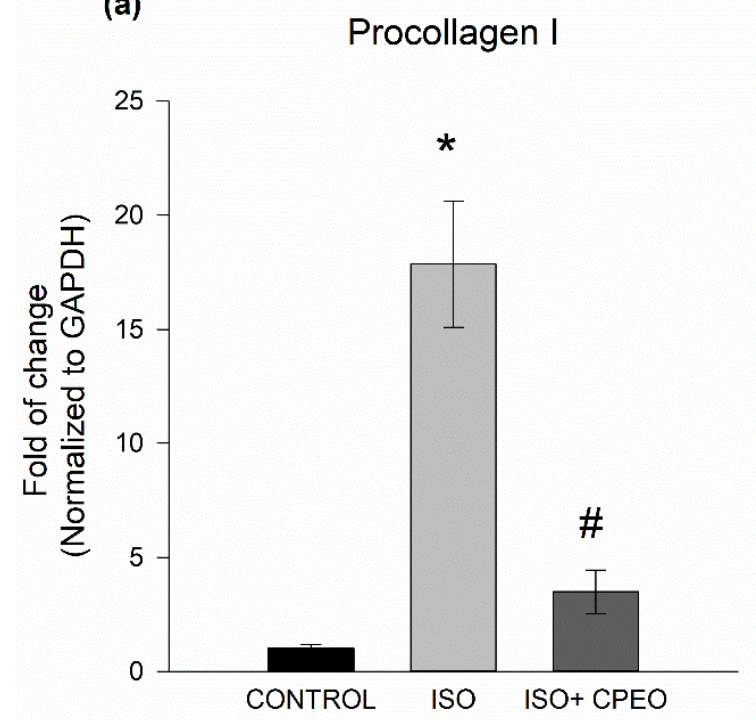

(b)

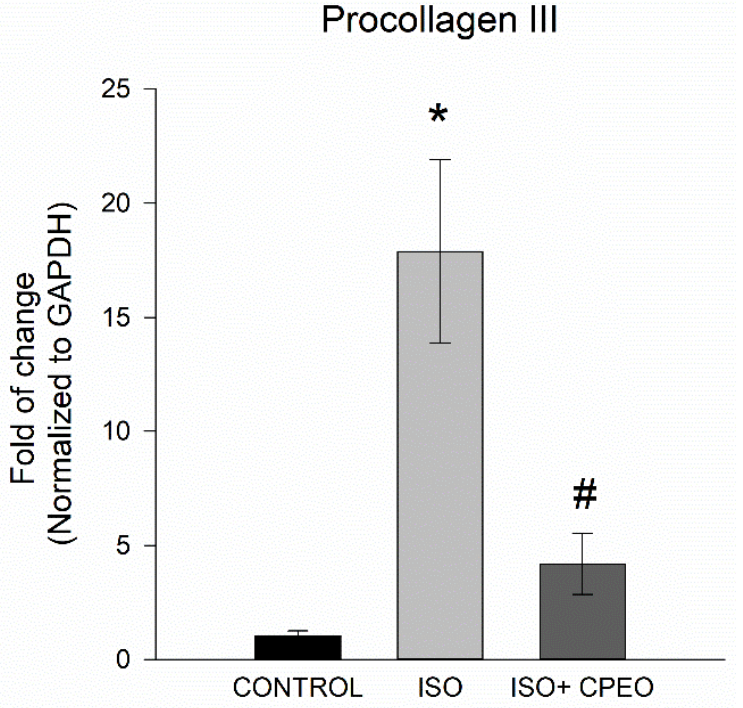

Figure 5. Effect of Cymbopogon proximus essential oil (CPEO) and/or isoproterenol (ISO) on levels of fibrosis markers. Male albino rats were injected intraperitoneally daily with vehicle, $\mathrm{CPEO}(800 \mu \mathrm{L} / \mathrm{kg} / \mathrm{d})$, ISO $(5 \mathrm{mg} / \mathrm{kg})$, or CPEO $(800 \mu \mathrm{L} / \mathrm{kg} / \mathrm{d})$ plus ISO $(5 \mathrm{mg} / \mathrm{kg})$. Oil administration was started four days prior to ISO administration and continued concurrently thereafter for an additional $3 \mathrm{~d}$. Gene expression levels of fibrosis markers Pro I (a) and Pro III (b) were determined in the heart using quantitative real-time polymerase chain reaction. The results are presented as the means of six independent experiments \pm SEM. ${ }^{*} p<0.05$ compared to control, $\# p<0.05$ compared to ISO-treated rats.

\section{Discussion}

The results of the present study provide the first evidence that $C$. proximus may confer cardioprotection against cardiac remodeling. Despite advances made in cardiovascular research over the last decades, therapeutic options available for the treatment for HF are limited to agents that either delay disease progression such as $\beta$-blockers or only control symptoms such as diuretics [28]. Hence, there is an urgent need to identify new therapeutic agents that either prevent the initiation of $\mathrm{HF}$ in high risk patients or regress cardiac hypertrophy during its progression [29]. Over the years, plants have been highly valued around the world as a rich source of therapeutic agents for the treatment and prevention of numerous diseases and illnesses. It is estimated that $80 \%$ of cardiovascular drugs are derived from plant origins [30,31]. However, to the best of our knowledge, there has been no research conducted to investigate the cardioprotective effect of $C$. proximus against cardiac remodeling. Therefore, the current study was performed to examine the capacity of $C$. proximus to protect rats from isoproterenol-induced cardiac hypertrophy and fibrosis.

Our study revealed cardioprotective effects of $C$. proximus against isoproterenol-induced cardiac hypertrophy and fibrosis. These findings are evidenced by the prevention of increased HW/BW ratios caused by the administration of isoproterenol to rats pretreated with C. proximus oil, which maintained ratios close to those of the control group. In addition, C. proximus precluded elevated levels of hypertrophy markers caused by isoproterenol treatment as demonstrated through significant reduction in mRNA levels of ANP, BNP, and $\beta$-MHC. Moreover, isoproterenol treatment caused deterioration in cardiomyocyte architecture and increased cell surface area. However, C. proximus attenuated these observed effects when administrated prior to the administration of isoproterenol. Histological analysis 
revealed that isoproterenol treatment induced fibrosis by increasing collagen deposition in the heart. The induction of CVF by isoproterenol was significantly prevented in the group of animals pretreated with C. proximus oil, which indicated C. proximus had the ability to protect the heart from myocardial fibrosis, a hallmark of cardiac remodeling. Furthermore, isoproterenol-induced elevated mRNA levels of fibrosis markers, including Pro I and Pro III, were significantly reversed by pretreatment with C. proximus oil. The dose of C. proximus used in our study was chosen based on the study of El Tahir et al. [24]. In their study, C. proximus oil causes significant changes in the heart rate only after the administration of the oil at a higher dose $(1600 \mu \mathrm{L} / \mathrm{kg})$. However, $800 \mu \mathrm{L} / \mathrm{kg}$ did not cause significant changes in the heart rate [24]. Therefore, it is unlikely that the effects observed in our study are due to heart rate changes. In addition, C. proximus has been shown to exhibit a hypotensive effect in normotensive rats and protect against (L-NAME)-induced hypertension [23,24]. However, it is evident that repeated administration of small doses of isoproterenol to animals causes cardiac hypertrophy and fibrosis without changing the blood pressure [32-34]. Thus, it is highly unlikely that C. proximus acted as an antihypertensive agent in the absence of hypertensive stimuli in our study. Interestingly, several species of Cymbopogon are reported to possess cardiovascular benefiting properties. For instance, extracts of $C$. citratus have been shown to protect against isoproterenol-induced cardiotoxicity [35]. Moreover, extracts from C. citratus and C. winterianus are shown to reduce blood pressure by modulating the calcium pathway and decreasing heart rate by activating cardiac muscarinic receptors [36,37]. Also, C. citratus and C. jwarancusa extracts are reported to possess antioxidant, antidiabetic, and hypolipidemic properties and protect against endothelial dysfunction [10-12,17,18,21]. Of specific interest, C. proximus extracts are reported to possess profound antioxidant effects and are able to decrease blood pressure in both normotensive and hypertensive rats $[21,23,24]$. Although the chemical compositions of these Cymbopogon species vary, they share some components. For instance, the essential oils of C. proximus and $C$. jwarancusa contain a considerable amount of piperitone, carene, $\beta$-caryophyllane, and elemol. Cymbopogon citratus and C. winterianus contain high amounts of geraniol, geranial, and cadinol isomers. Considerable amounts of elemol and limonene have also been reported in both C. proximus and C. winterianus [11,38-40]. Our present findings, along with the results of previous studies, highlight the potential protective effects of Cymbopogon species against CVDs.

Several molecular responses and molecules are well documented to play pivotal roles in the development of cardiac dysfunction and hypertrophy. These include, but are not limited to, inflammatory cytokines, matrix metalloproteinase, oxidative stress, and apoptosis [41,42]. Based on results obtained from GC-MS analysis, the crude C. proximus essential oil was comprised of various components that ranged in volume from $0.105 \%$ to $23.54 \%$. These findings are consistent with an analysis previously reported [24]. Interestingly, some of the components identified are reported to exhibit various effects on the aforementioned signaling molecules of cardiac hypertrophy. For instance, thymol is reported to protect the heart against isoproterenol-induced myocardial infarction and cardiac hypertrophy via anti-apoptotic effect [43]. In addition, elemol, $\beta$-elemene, terpinolene, $\beta$-caryophyllene, and thymol, which represented more than $33 \%$ of the total essential oil, are known to suppress several pro-inflammatory cytokines, including TNF- $\alpha$, IL-1 $\beta$, and IL-6 [44-48]. In addition, production of pro-inflammatory cytokines IL-4, IL-8, and IL-12 was inhibited by elemol, thymol, and $\beta$-elemene, respectively [49-51]. Moreover, $\beta$-caryophyllene decreased the production of matrix metalloproteinases MMP-3 and MMP-9 and the pro-apoptotic markers Bax, p53, and active caspase-3 [45,52,53]. In addition, the major C. proximus essential oil extract constituents $\alpha$-eudesmol and $\beta$-eudesmol protect cells from apoptosis by increasing levels of antioxidant enzymes. These pathways counteract the effects of free radicals by decreasing NADPH oxidase and the production of superoxide [54,55]. Modulations of these pathways using genetic approaches and/or pharmacological interventions are shown to be protective against cardiac dysfunction $[41,42]$. These findings suggest a possible mechanism by which C. proximus and its constituents may have produced the protective effects reported in our current study. Identifying the major active constituents of $C$. proximus essential oil, along with the potential mechanisms responsible for the protective effect, requires additional investigation. 


\section{Materials and Methods}

\subsection{Chemicals and Reagents}

Isoproterenol was obtained from Sigma-Aldrich (St. Louis, MO, USA) and TRIzol reagent was purchased from Invitrogen Co. (Grand Island, NY, USA). The High-Capacity cDNA Reverse Transcription Kit (Catalog\# 4368814) and SYBR ${ }^{\circledR}$ Green PCR Master Mix (Catalog\# 4309155) were purchased from Applied Biosystems (Foster City, CA, USA). Hematoxylin and eosin (H\&E) and Masson's trichrome staining kits were purchased from Nanjing SenBeiJia Biological Technology Co., Ltd. (Nanjing, China). Real-time polymerase chain reaction (PCR) primers were designed by members of our laboratory and synthesized by Integrated DNA Technologies Incorporation (San Diego, CA, USA). The primer sequences are shown in Table 2.

Table 2. Sequences of primers used for real-time polymerase chain reaction.

\begin{tabular}{ccc}
\hline Gene & Forward Primer $\left(5^{\prime}-\mathbf{3}^{\prime}\right)$ & Reverse Primer $^{\left(5^{\prime}-\mathbf{3}^{\prime}\right)}$ \\
\hline ANP $^{\mathrm{a}}$ & GCTTCGGGGGTAGGATTGACA & GGCAATGCGACCAAGCTGT \\
BNP $^{\mathrm{b}}$ & TTTCCTTAATCTGTCGCCGCT & CTAAAACAACCTCAGCCCGTCA \\
$\boldsymbol{\beta}^{\mathrm{M} H \mathrm{MC}^{\mathrm{c}}}$ & GCCGAGTCCCAGGTCAACAA & GTAATTCGAGGGCAGGAACCC \\
Pro I $^{\mathrm{d}}$ & CGGCTCCTGCTCCTCTTAGG & CACTCGCCCTCCCGTTTTTG \\
Pro III $^{\mathrm{e}}$ & TGGGATGCAACTACCTTGGT & AGGTGTAGAAGGCTGTGGAC \\
GAPDH $^{\mathrm{f}}$ & CAGTGCCAGCCTCGTCTCAT & CAAGAGAAGGCAGCCCTGGT \\
\hline
\end{tabular}

$\overline{{ }^{a}}$ atrial natriuretic peptide; ${ }^{b}$ brain natriuretic peptide; ${ }^{c} \beta$-myosin heavy chain; ${ }^{d}$ procollagen I; ${ }^{e}$ procollagen III; ${ }^{f}$ glyceraldehyde 3-phosphate dehydrogenase.

\subsection{Plant Material}

C. Proximus (Hochst. ex A. Rich.) Stapf, family Poaceae was purchased from a local market in Alexandria, Egypt. The identity of the plant material was confirmed by Prof Saniya Kamal at the Department of Botany, College of Science, Alexandria University, Alexandria, Egypt.

\subsection{Preparation of C. Proximus Oil}

Essential oil was prepared from dry powdered C. proximus plant material (250 gm) using a hydrodistillation method for a period of $5 \mathrm{~h}$ [56]. The essential oil was separated and dried over anhydrous sodium sulphate, which yielded a $5.4 \% w / w$ final product.

\subsection{GC/MS Analysis}

GC/MS analysis was carried out using an Agilent 7890 Gas Chromatograph (Agilent, Santa Clara, CA, USA) with an MSD System equipped with a HP-5MS capillary column $(30 \mathrm{~m} \times 0.25 \mathrm{~mm}$ i.d., $0.25 \mu \mathrm{m}$ coating). Aliquots $(1 \mathrm{~mL})$ of $C$. Proximus oil diluted to a concentration of 5 parts per million (ppm) were then injected into the GC/MS autosampler using the split-less mode. The column temperature was maintained at $70{ }^{\circ} \mathrm{C}$ for $5 \mathrm{~min}$ and programmed to then increase at a rate of $5^{\circ} \mathrm{C} / \mathrm{min}$ to $290{ }^{\circ} \mathrm{C}$, which was isothermally held for $5 \mathrm{~min}$. The detector and injector temperatures were $290{ }^{\circ} \mathrm{C}$ and $280{ }^{\circ} \mathrm{C}$, respectively. The carrier gas was helium (99.999\% purity) at a flow rate of $1.0 \mathrm{~mL} / \mathrm{min}$. The significant quadrupole mass analyzer (QMS) operating parameters included electrospray ionization at $70 \mathrm{eV}$ with a scan mass range of 30 to $600 \mathrm{~m} / \mathrm{z}$. The C. proximus oil components were identified by comparing their mass spectra with the National Institute of Standards and Technology (NIST 2017) database. The analysis and processing of the results were controlled using MassHunter software (Agilent Technologies Inc., Santa Clara, CA, USA). The identity of peaks was verified by comparing their mass spectra against commercially available libraries (Wiley GC/MS Library, MassFinder 3 Library) as previously described [57,58]. 


\subsection{Gas Chromatography (GC) Analysis}

GC spectra obtained under the conditions described above were used to identify each peak by comparing their respective relative retention index (RRI) to a series of n-alkanes. The quantity of each compound was estimated based on computerized peak area measurements.

\subsection{Animals}

The study complied with the Law of Ethics of Research on Living Creatures published by the National Committee of BioEthics (NCBE), Saudi Arabia and the National Institutes of Health Guide for the Care and Use of Laboratory Animals (NIH Publications No. 8023, revised 1978). All experimental procedures involving animals were approved by the Bioethics Committee, Prince Sattam Bin Abdulaziz University (No. 201902003). Male albino rats weighing 200-250 g were obtained from the Lab Animal Care Unit, Pharmacy College, Prince Sattam Bin Abdulaziz University (Al-Kharj, KSA). All animals were housed on a 12-h light/dark cycle with food and water available ad libitum.

\subsection{Experimental Design and Treatment Protocol}

Male albino rats were randomly divided into four groups (6 rats/group). The first group received a daily intraperitoneal (IP) injection of vehicle (saline + olive oil). The second group received a daily IP injection of C. proximus oil $(800 \mu \mathrm{L} / \mathrm{kg} / \mathrm{d})$ with the dose being based on a previous report [24]. The third group received a daily IP injection of isoproterenol $(5 \mathrm{mg} / \mathrm{kg} / \mathrm{d})$. The fourth group received a daily IP injection of both isoproterenol $(5 \mathrm{mg} / \mathrm{kg} / \mathrm{d})$ and C. proximus oil $(800 \mu \mathrm{L} / \mathrm{kg} / \mathrm{d})$. The administration of oil was started four days prior to the isoproterenol administration and continued concurrently thereafter for an additional $3 \mathrm{~d}$. The dose and period of isoproterenol administration were selected based on our previous study [8]. All animal groups were euthanized $24 \mathrm{~h}$ after the last dose of treatment. Hearts were quickly excised, washed with saline, blotted with filter paper, and measured, followed by immediately being frozen in liquid nitrogen. The hearts were stored at $-80^{\circ} \mathrm{C}$ until further analysis.

\subsection{Histological Examination}

For histological examinations, heart cross-sections were immediately collected after sacrificing the animals and fixed in $4 \%$ formalin at room temperature. The tissues were embedded with paraffin and cut into 3- $\mu \mathrm{m}$ thick sections. The tissue sections were then deparaffinized with xylene and rehydrated with graded ethanol prior to histological staining. For structural analysis, hear tissue sections were stained with H\&E using a standard protocol. Images were obtained using a Leica SCN400 Slide Scanner (Leica Biosystems, Wetzlar, Germany) at $200 \times$ magnification. The images were then analyzed using Leica SCN400 Image Viewer software. Random microscopic fields of sections from each animal were selected for analysis. Cell surface area (CSA) of randomly selected cardiomyocytes (10-15 per section) was measured using ImageJ software (National Institute of Health, Bethesda, MD, USA). To visualize and measure collagen deposits, heart tissue sections were stained with Masson's trichrome according to standard methods. Fibrous tissue stained blue, cytoplasm red, and the cell nuclei black. Cardiac fibrosis was visualized at $200 \times$ magnification using the Leica SCN400 Slide Scanner and the images analyzed using the Leica SCN400 Image Viewer software. CVF was quantified by calculating the area percentage of collagen staining using ImageJ software.

\subsection{RNA Extraction and Complementary DNA (cDNA) Synthesis}

Total RNA was isolated from the frozen tissues using TRIzol reagent according to the manufacturer's instructions and quantified by measuring absorbance at $260 \mathrm{~nm}$ using a Genova Nano micro-volume spectrophotometer (Jenway ${ }^{\circledR}$, Staffordshire, UK). Purity of the RNA was determined according to 260/280 absorbance ratios (>1.8). First strand cDNA was synthesized using a HighCapacity cDNA Reverse Transcription Kit, according to the manufacturer provided instructions. Briefly, $1.5 \mu \mathrm{g}$ of total RNA from each sample was added to a mixture of $2.0 \mu \mathrm{L} 10 \times$ reverse transcriptase 
buffer, $0.8 \mu \mathrm{L} 25 \times \mathrm{dNTP} \operatorname{mix}(100 \mathrm{mM}$ each), $2.0 \mu \mathrm{L}$ 10× reverse transcriptase random primers, $1.0 \mu \mathrm{L}$ MultiScribe reverse transcriptase, and $4.2 \mu \mathrm{L}$ nuclease-free water. The final reaction mixture was maintained at $25^{\circ} \mathrm{C}$ for $10 \mathrm{~min}$, heated to $37^{\circ} \mathrm{C}$ for $120 \mathrm{~min}$, heated to $85^{\circ} \mathrm{C}$ for $5 \mathrm{~min}$, and finally cooled to $4{ }^{\circ} \mathrm{C}$.

\subsection{Quantification of $m R N A$ Expression by Quantitative Real-Time PCR}

Quantitative analysis of specific mRNA expression was performed using real time-PCR. Briefly, $1.5 \mu \mathrm{g}$ cDNA was subjected to PCR amplification using 96-well optical reaction plates in an ABI Prism 7500 System (Applied Biosystems, Foster City, CA, USA) according to the manufacturer's

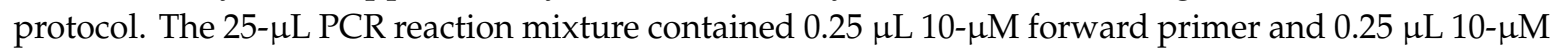
reverse primer (100 nM final concentration of each primer), $12.5 \mu \mathrm{L}$ SYBR Green Universal Master Mix, 10.6 $\mu \mathrm{L}$ nuclease-free water, and $1.4 \mu \mathrm{L}$ cDNA as template. Rat primer sequences for atrial natriuretic peptide (ANP), brain natriuretic peptide (BNP), $\beta$-myosin heavy chain $(\beta-\mathrm{MHC})$, procollagen I (Pro I), procollagen III (Pro III), and glyceraldehyde 3-phosphate dehydrogenase (GAPDH) are listed in Table 2. The real- time PCR data was analyzed as relative gene expression using the $2-\Delta \Delta \mathrm{Ct}$ method as previously described [59]. Briefly, the fold change in levels of target genes between the treated and untreated groups were normalized to the level of GAPDH and compared according to the following equation: fold change $=2-\Delta(\Delta \mathrm{Ct})$, where $\Delta \mathrm{Ct}=\mathrm{Ct}($ target $)-\mathrm{Ct}(\mathrm{GAPDH})$ and $\Delta(\Delta \mathrm{Ct})=\Delta \mathrm{Ct}($ treated $)$ $-\Delta \mathrm{Ct}$ (untreated).

\subsection{Statistical Analysis}

Statistical analysis of the results from the different experimental groups was performed using SigmaPlot ${ }^{\circledR}$ for Windows (Systat Software, Inc, CA, USA). All data are expressed as means \pm SEM. One- way analysis of variance (ANOVA) followed by the Tukey-Kramer multiple comparison test was conducted to assess significant differences between treatment groups. Duplicate reactions were performed for each experiment and the results are presented as the means of six independent experiments \pm S.E.M. The differences were considered statistically significant when $p<0.05$.

\section{Conclusions}

Our study revealed the cardioprotective effects of C. proximus essential oil against isoproterenolinduced cardiac hypertrophy and fibrosis. These findings were evidenced by first, significant decreases in HW/BW ratios; second, significant decreases of hypertrophy markers ANP, BNP, and $\beta$-MHC mRNA levels; third, significant decreases of fibrosis markers Pro I and Pro III mRNA levels; and fourth, significant decreases in CVF and the inhibition of cardiomyocyte architecture deterioration caused by isoproterenol. Together, these findings pinpoint the importance of $C$. proximus as a potential treatment for cardiac diseases. While the cardioprotective effects of $C$. proximus essential oil were clear, the current findings lack details regarding the correlation between pure components of the essential oil extract and the observed effects. This limitation may be addressed in a future study.

Author Contributions: Conceptualization, H.N.A., M.S.A.-K., K.M.A., and F.F.A.; methodology, H.N.A., M.S.A.-K., K.M.A., and F.F.A.; validation, H.N.A., M.S.A.-K., K.M.A., and F.F.A.; Formal analysis, H.N.A., M.S.A.-K., K.M.A., M.A.S. and F.F.A.; investigation, H.N.A., M.S.A.-K., K.M.A., and F.F.A.; writing-original draft preparation, H.N.A., M.S.A.-K., K.M.A., and F.F.A.; writing-review and editing, H.N.A., M.S.A.-K., K.M.A., and F.F.A. All authors have read and agreed to the published version of the manuscript.

Funding: This research was funded by the Deanship of Scientific Research at Prince Sattam Bin Abdulaziz University, grant number [2016/03/6630].

Acknowledgments: The authors thank Abubaker M. Hamad for technical assistance in performing the histological examinations.

Conflicts of Interest: The authors declare no conflict of interest. The funders had no role in the design of the study; in the collection, analyses, or interpretation of data; in the writing of the manuscript, or in the decision to publish the results. 


\section{References}

1. Benjamin, E.J.; Muntner, P.; Alonso, A.; Bittencourt, M.S.; Callaway, C.W.; Carson, A.P.; Chamberlain, A.M.; Chang, A.R.; Cheng, S.; Das, S.R.; et al. Heart Disease and Stroke Statistics-2019 Update: A Report From the American Heart Association. Circulation 2019, 139, e56-e528. [CrossRef] [PubMed]

2. World Health Organization Cardiovascular Diseases (CVDs). 2017. Available online: https://www.who.int/ news-room/fact-sheets/detail/cardiovascular-diseases-(cvds) (accessed on 1 March 2020).

3. Dzau, V.; Braunwald, E. Resolved and unresolved issues in the prevention and treatment of coronary artery disease: A workshop consensus statement. Am. Heart J. 1991, 121, 1244-1263. [CrossRef]

4. Dzau, V.J.; Antman, E.M.; Black, H.R.; Hayes, D.L.; Manson, J.E.; Plutzky, J.; Popma, J.J.; Stevenson, W. The cardiovascular disease continuum validated: Clinical evidence of improved patient outcomes: Part I: Pathophysiology and clinical trial evidence (risk factors through stable coronary artery disease). Circulation 2006, 114, 2850-2870. [CrossRef]

5. Savarese, G.; Lund, L.H. Global public health burden of heart failure. Card. Fail. Rev. 2017, 3, 7-11. [CrossRef]

6. Jones, N.R.; Hobbs, F.R.; Taylor, C.J. Prognosis following a diagnosis of heart failure and the role of primary care: A review of the literature. BJGP open 2017, 1, bjgpopen17X101013. [CrossRef]

7. Chrysant, S.G. A new paradigm in the treatment of the cardiovascular disease continuum: Focus on prevention. Hippokratia 2011, 15, 7-11.

8. Althurwi, H.N.; Maayah, Z.H.; Elshenawy, O.H.; El-Kadi, A.O.S. Early changes in cytochrome P450s and their associated arachidonic acid metabolites play a crucial role in the initiation of cardiac hypertrophy induced by isoproterenol. Drug Metab. Dispos. 2015, 43, 1254-1266. [CrossRef] [PubMed]

9. Lüscher, T.F. Predictors as well as surrogate and hard endpoints in cardiovascular disease. Eur. Heart J. 2015, 36, 2197-2199. [CrossRef] [PubMed]

10. Avoseh, O.; Oyedeji, O.; Rungqu, P.; Nkeh-Chungag, B.; Oyedeji, A. Cymbopogon species; ethnopharmacology, phytochemistry and the pharmacological importance. Molecules 2015, 20, 7438-7453. [CrossRef]

11. Dutta, S.; Munda, S.; Lal, M.; Bhattacharyya, P.R. A short review on chemical composition therapeutic use and enzyme inhibition activities of Cymbopogon species. Indian J. Sci. Technol. 2016, 9, 1-9. [CrossRef]

12. Ganjewala, D. Cymbopogon essential oils: Chemical compositions and bioactivities. Int. J. Essent. Oil Ther. 2009, 3, 56-65.

13. Miguel, M.G. Antioxidant and anti-inflammatory activities of essential oils: A short review. Molecules 2010, 15, 9252-9287. [CrossRef]

14. Ekpenyong, C. Cymbopogon Citratus stapf (DC) extract ameliorates atherogenic cardiovascular risk in Diabetes-induced Dyslipidemia in rats. Br. J. Med. Med. Res. 2014, 4, 4695-4709. [CrossRef]

15. Mansour, H.A.; Newairy, A.S.A.; Yousef, M.I.; Sheweita, S.A. Biochemical study on the effects of some Egyptian herbs in alloxan-induced diabetic rats. Toxicology 2002, 170, 221-228. [CrossRef]

16. Adeneye, A.A.; Agbaje, E.O. Hypoglycemic and hypolipidemic effects of fresh leaf aqueous extract of Cymbopogon citratus Stapf. in rats. J. Ethnopharmacol. 2007, 112, 440-444. [CrossRef] [PubMed]

17. Campos, J.; Schmeda-Hirschmann, G.; Leiva, E.; Guzmán, L.; Orrego, R.; Fernández, P.; González, M.; Radojkovic, C.; Zuñiga, F.A.; Lamperti, L.; et al. Lemon grass (Cymbopogon citratus (D.C) Stapf) polyphenols protect human umbilical vein endothelial cell (HUVECs) from oxidative damage induced by high glucose, hydrogen peroxide and oxidised low-density lipoprotein. Food Chem. 2014, 151, 175-181. [CrossRef]

18. Khan, S.J.; Afroz, S.; Khan, R.A. Antihyperlipidemic and anti-hyperglycemic effects of Cymbopogon jwarancusa in high-fat high-sugar Diet model. Pak. J. Pharm. Sci. 2018, 31, 1341-1345.

19. El-Askary, H.; Meselhy, M.; Galal, A. Sesquiterpenes from Cymbopogon proximus. Molecules 2003, 8, 670-677. [CrossRef]

20. Ibrahim, F.Y.; El-Khateeb, A.Y. Effect of herbal beverages of Foeniculum vulgare and Cymbopogon proximus on inhibition of calcium oxalate renal crystals formation in rats. Ann. Agric. Sci. 2013, 58, 221-229. [CrossRef]

21. Selim, S.A. Chemical composition, antioxidant and antimicrobial activity of the essential oil and methanol extract of the Egyptian lemongrass Cymbopogon proximus Stapf. Grasas y Aceites 2011, 62, 55-61. [CrossRef]

22. Warrag, N.M.; Tag Eldin, I.M.; Ahmed, E.M. Effect of Cymbopogon proximus (Mahareb) on ethylene glycol-induced nephrolithiasis in rats. African J. Pharm. Pharmacol. 2014, 8, 443-450. 
23. El-Nezhawy, A.O.H.; Maghrabi, I.A.; Mohamed, K.M.; Omar, H.A. Cymbopogon proximus extract decreases L-NAME-induced hypertension in rats. Int. J. Pharm. Sci. Rev. Res. 2014, 27, 66-69.

24. El Tahir, K.; Abdel-Kader, M. Chemical and pharmacological study of Cymbopogon proximus volatile oil. Res. J. Med. Plant 2008, 2, 53-60.

25. Kuwahara, K.; Nishikimi, T.; Nakao, K. Transcriptional regulation of the fetal cardiac gene program. J. Pharmacol. Sci. 2012, 119, 198-203. [CrossRef] [PubMed]

26. Rajabi, M.; Kassiotis, C.; Razeghi, P.; Taegtmeyer, H. Return to the fetal gene program protects the stressed heart: A strong hypothesis. Heart Fail. Rev. 2007, 12, 331-343. [CrossRef] [PubMed]

27. Iemitsu, M.; Miyauchi, T.; Maeda, S.; Sakai, S.; Kobayashi, T.; Fujii, N.; Miyazaki, H.; Matsuda, M.; Yamaguchi, I. Physiological and pathological cardiac hypertrophy induce different molecular phenotypes in the rat. Am. J. Physiol. Regul. Integr. Comp. Physiol. 2001, 281, R2029-R2036. [CrossRef]

28. Machaj, F.; Dembowska, E.; Rosik, J.; Szostak, B.; Mazurek-Mochol, M.; Pawlik, A. New therapies for the treatment of heart failure: A summary of recent accomplishments. Ther. Clin. Risk Manag. 2019, 15, 147-155. [CrossRef]

29. Chapman, B.; DeVore, A.D.; Mentz, R.J.; Metra, M. Clinical profiles in acute heart failure: An urgent need for a new approach. ESC Hear. Fail. 2019, 6, 464-474. [CrossRef]

30. Koo, Y.E.; Song, J.; Bae, S. Use of plant and herb derived medicine for therapeutic usage in cardiology. Medicines 2018, 5, 38. [CrossRef]

31. Pan, S.Y.; Zhou, S.F.; Gao, S.H.; Yu, Z.L.; Zhang, S.F.; Tang, M.K.; Sun, J.N.; Ma, D.L.; Han, Y.F.; Fong, W.F.; et al. New perspectives on how to discover drugs from herbal medicines: CAM'S outstanding contribution to modern therapeutics. Evidence-Based Complement. Altern. Med. 2013, 2013, 627375. [CrossRef]

32. Nichtova, Z.; Novotova, M.; Kralova, E.; Stankovicova, T. Morphological and functional characteristics of models of experimental myocardial injury induced by isoproterenol. Gen. Physiol. Biophys. 2012, 31, 141-151. [CrossRef] [PubMed]

33. Leenen, F.H.; White, R.; Yuan, B. Isoproterenol-induced cardiac hypertrophy: Role of circulatory versus cardiac renin-angiotensin system. Am. J. Physiol. Heart Circ. Physiol. 2001, 281, H2410-H2416. [CrossRef] [PubMed]

34. Ryu, Y.; Jin, L.; Kee, H.J.; Piao, Z.H.; Cho, J.Y.; Kim, G.R.; Choi, S.Y.; Lin, M.Q.; Jeong, M.H. Gallic acid prevents isoproterenol-induced cardiac hypertrophy and fibrosis through regulation of JNK2 signaling and Smad3 binding activity. Sci. Rep. 2016, 6, 34790. [CrossRef] [PubMed]

35. Gayathri, K.; Jayachandran, K.S.; Vasanthi, H.R.; Rajamanickam, G.V. Cardioprotective effect of lemon grass as evidenced by biochemical and histopathological changes in experimentally induced cardiotoxicity. Hum. Exp. Toxicol. 2011, 30, 1073-1082. [CrossRef]

36. De Menezes, I.A.C.; Moreira, Í.J.A.; De Paula, J.W.A.; Blank, A.F.; Antoniolli, A.R.; Quintans-Júnior, L.J.; Santos, M.R.V. Cardiovascular effects induced by Cymbopogon winterianus essential oil in rats: Involvement of calcium channels and vagal pathway. J. Pharm. Pharmacol. 2010, 62, 215-221. [CrossRef]

37. Gazola, R.; MacHado, D.; Ruggiero, C.; Singi, G.; MacEdo Alexandre, M. Lippia alba, Melissa officinalis and Cymbopogon citratus: Effects of the aqueous extracts on the isolated hearts of rats. Pharmacol. Res. 2004, 50, 477-480. [CrossRef]

38. Simic, A.; Rančic, A.; Sokovic, M.D.; Ristic, M.; Vukojevic, J.; Marin, P.D.; Rančic, A.; Sokovic, M.D.; Ristic, M.; Simic, A.; et al. Essential Oil Composition of Cymbopogon winterianus. and Carum carvi. and Their Antimicrobial Activities Essential Oil Composition of Cymbopogon winterianus and Carum carvi and Their Antimicrobial Activities. Pharm. Biol. 2008, 46, 437-441. [CrossRef]

39. Gbenou, J.D.; Ahounou, J.F.; Akakpo, H.B.; Laleye, A.; Yayi, E.; Gbaguidi, F.; Baba-Moussa, L.; Darboux, R.; Dansou, P.; Moudachirou, M.; et al. Phytochemical composition of Cymbopogon citratus and Eucalyptus citriodora essential oils and their anti-inflammatory and analgesic properties on Wistar rats. Mol. Biol. Rep. 2013, 40, 1127-1134. [CrossRef]

40. Moreira, F.V.; Bastos, J.F.A.; Blank, A.F.; Alves, P.B.; Santos, M.R.V. Composição química e efeitos cardiovasculares do óleo essencial de Cymbopogon citratus DC. Stapf, Poaceae, em ratos. Brazilian J. Pharmacogn. 2010, 20, 904-909. [CrossRef] 
41. Schirone, L.; Forte, M.; Palmerio, S.; Yee, D.; Nocella, C.; Angelini, F.; Pagano, F.; Schiavon, S.; Bordin, A.; Carrizzo, A.; et al. A Review of the molecular mechanisms underlying the development and progression of cardiac remodeling. Oxid. Med. Cell. Longev. 2017, 2017, 1-16. [CrossRef] [PubMed]

42. Kehat, I.; Molkentin, J.D. Molecular pathways underlying cardiac remodeling during pathophysiological stimulation. Circulation 2010, 122, 2727-2735. [CrossRef]

43. Fizur, M.; Meeran, N.; Jagadeesh, G.S.; Selvaraj, P. Thymol attenuates altered lipid metabolism in $\beta$-adrenergic agonist induced myocardial infarcted rats by inhibiting tachycardia, altered electrocardiogram, apoptosis and cardiac hypertrophy. J. Funct. Foods 2015, 14, 51-62.

44. Kwon, H., II; Jeong, N.H.; Kim, S.Y.; Kim, M.H.; Son, J.H.; Jun, S.H.; Kim, S.; Jeon, H.; Kang, S.C.; Kim, S.H.; et al. Inhibitory effects of thymol on the cytotoxicity and inflammatory responses induced by Staphylococcus aureus extracellular vesicles in cultured keratinocytes. Microb. Pathog. 2019, 134, 103603. [CrossRef] [PubMed]

45. Al-Taee, H.; Azimullah, S.; Meeran, M.F.N.; Alaraj Almheiri, M.K.; Al Jasmi, R.A.; Tariq, S.; Ab Khan, M.; Adeghate, E.; Ojha, S. $\beta$-caryophyllene, a dietary phytocannabinoid attenuates oxidative stress, inflammation, apoptosis and prevents structural alterations of the myocardium against doxorubicin-induced acute cardiotoxicity in rats: An in vitro and in vivo study. Eur. J. Pharmacol. 2019, 858, 172467. [CrossRef] [PubMed]

46. Chamanara, M.; Abdollahi, A.; Rezayat, S.M.; Ghazi-Khansari, M.; Dehpour, A.; Nassireslami, E.; Rashidian, A. Thymol reduces acetic acid-induced inflammatory response through inhibition of NF-kB signaling pathway in rat colon tissue. Inflammopharmacology 2019, 27, 1275-1283. [CrossRef]

47. de Christo Scherer, M.M.; Marques, F.M.; Figueira, M.M.; Peisino, M.C.O.; Schmitt, E.F.P.; Kondratyuk, T.P.; Endringer, D.C.; Scherer, R.; Fronza, M. Wound healing activity of terpinolene and $\alpha$-phellandrene by attenuating inflammation and oxidative stress in vitro. J. Tissue Viability 2019, 28, 94-99. [CrossRef]

48. Meng, X.; Li, N.; Zhang, Y.; Fan, D.; Yang, C.; Li, H.; Guo, D.; Pan, S. Beneficial effect of $\beta$-elemene alone and in combination with hyperbaric oxygen in traumatic brain injury by inflammatory pathway. Transl. Neurosci. 2018, 9, 33-37. [CrossRef]

49. Yang, H.; Jung, E.-M.; Ahn, C.; Lee, G.-S.; Lee, S.-Y.; Kim, S.-H.; Choi, I.-G.; Park, M.-J.; Lee, S.-S.; Choi, D.-H.; et al. Elemol from Chamaecyparis obtusa ameliorates 2,4-dinitrochlorobenzene-induced atopic dermatitis. Int. J. Mol. Med. 2015, 36, 463-472. [CrossRef]

50. Nagoor Meeran, M.F.; Javed, H.; Al Taee, H.; Azimullah, S.; Ojha, S.K. Pharmacological properties and molecular mechanisms of thymol: Prospects for its therapeutic potential and pharmaceutical development. Front. Pharmacol. 2017, 8, 380. [CrossRef]

51. Li, X.; Lin, Z.; Zhang, B.; Guo, L.; Liu, S.; Li, H.; Zhang, J.; Ye, Q. ß-elemene sensitizes hepatocellular carcinoma cells to oxaliplatin by preventing oxaliplatin-induced degradation of copper transporter 1. Sci. Rep. 2016, 6, 21010. [CrossRef]

52. Kim, C.; Cho, S.K.; Kim, K.-D.; Nam, D.; Chung, W.-S.; Jang, H.-J.; Lee, S.-G.; Shim, B.S.; Sethi, G.; Ahn, K.S. $\beta$-Caryophyllene oxide potentiates TNF $\alpha$-induced apoptosis and inhibits invasion through down-modulation of NF-kB-regulated gene products. Apoptosis 2014, 19, 708-718. [CrossRef] [PubMed]

53. Cho, J.Y.; Kim, H.Y.; Kim, S.-K.; Park, J.H.Y.; Lee, H.J.; Chun, H.S. $\beta$-Caryophyllene attenuates dextran sulfate sodium-induced colitis in mice via modulation of gene expression associated mainly with colon inflammation. Toxicol. Rep. 2015, 2, 1039-1045. [CrossRef] [PubMed]

54. Ben Sghaier, M.; Mousslim, M.; Pagano, A.; Ammari, Y.; Luis, J.; Kovacic, H. $\beta$-eudesmol, a sesquiterpene from Teucrium ramosissimum, inhibits superoxide production, proliferation, adhesion and migration of human tumor cell. Environ. Toxicol. Pharmacol. 2016, 46, 227-233. [CrossRef]

55. Nishiyama, T.; Masuda, Y.; Izawa, T.; Ohnuma, T.; Ogura, K.; Hiratsuka, A. Magnolol protects PC12 cells from hydrogen peroxide or 6-hydroxydopamine induced cytotoxicity. J. Toxicol. Sci. 2019, 44, 753-758. [CrossRef]

56. Meyer-warnod, B. Natural Essential Oils: Extraction processes and applications to some major Oils. Perfum. Flavorist 1984, 9, 93-103.

57. McLafferty, F.W.; Stauffer, D.B. The Wiley/NBS Registry of Mass Spectral Data; Wiley: New York, NY, USA, 1989. 
58. Zaghloul, A.M.; Abd El-Fattah, H.; Halim, A.F. Chemical investigation of the aerial parts of Anthemis melampodina. J. Pharm. Sci. 1989, 5, 23-33.

59. Livak, K.J.; Schmittgen, T.D. Analysis of relative gene expression data using real-time quantitative PCR and the 2(-Delta Delta C(T)) Method. Methods 2001, 25, 402-408. [CrossRef]

Sample Availability: Samples of the C. proximus oil are available from the authors.

(C) 2020 by the authors. Licensee MDPI, Basel, Switzerland. This article is an open access article distributed under the terms and conditions of the Creative Commons Attribution (CC BY) license (http://creativecommons.org/licenses/by/4.0/). 